\title{
Sustainable development of the Russian Arctic regions
}

\author{
N. Didenko, D. Skripnuk, K. Kikkas \& O. Seeleva \\ St. Petersburg State Polytechnical University, Russia
}

\begin{abstract}
The paper describes a model of six econometric equations, which is used for the analysis of development sustainability of Chukotka autonomous district - one of the Russian Arctic regions. The paper analyzes the following spheres of human activities within the region: the social sphere, the industrial sphere and the environmental sphere. Each sphere is evaluated with indicators. The theoretical views of various researchers on sustainable development are analyzed and the definition of sustainable development of the spheres of human activity in the arctic region is given. Under sustainable development of the arctic region one should understand such dynamics of the development indicators of various spheres of human activity in the region that show growth of the human development potential. The human development potential can be estimated with the human development index (HDI). The paper includes methodological principles of creation of the model of six econometric equations for the analysis of development sustainability of the region. Each equation is an ADL-model, because the ADL-model allows for estimation of dependencies of different indicators of human activity on the current and past time series of other indicators. The endogenous and exogenous variables of the model were chosen. The algorithm of model parameters calculating is being discussed. The coefficients of the six econometric equations are calculated on the data of Chukotka autonomous district. The analysis of the results is presented. The methodological principles of model creation and the solving results can be used while working out the sustainable development strategy for municipality, or single arctic region, or even all the Russian arctic regions.

Keywords: sustainable development, econometric equations model, ADL-model, Arctic region.
\end{abstract}




\section{Introduction}

The object of analysis of the article is Chukotka autonomous district. This territory belongs to the regions of the Far North, which includes the whole Chukotka peninsula, the part of mainland and several islands (Wrangell island, Ion and Ratmanov islands and others).

The Chukotka territory is rich in water resources. There are more than 8000 rivers more than $10 \mathrm{~km}$ long. The majority of the rivers are mountainous. The rivers are primarily fed by snow and rainwater, with long periods of freezing (7-8 months) with intensive floods and uneven river flow. Some rivers are freezing up to the bottom with forming of ice barriers. Break-up of the rivers is often accompanied with congestions due to later break-up in the lower course.

The majority of the lakes are of thermo-karstic origin, only some of the lakes are situated in the mountainous part of the district. The lakes near the Arctic ocean are of lagoon origin, so they are with salt water. The majority of the lakes are with running water, some of the low-lying lakes become swampy.

There are 44 groundwater origins found, 19 of them are used.

The vast amounts of mineral resources can be found in the region. They are crude oil, natural gas, coal, gold, tin, wolfram, mercury, copper and uranium. In the sea sediments of the East Chukotka coastal area one can find single diamonds [1].

The population of the district is 50,555 people (2014, Rosstat). Population density is 0.07 pers./sq. km. (2014). The urban population is $67.47 \%$ (2014).

Industry. The industrial development began in the late 1930s. It was extraction of hard and brown coal, that is up to now is used in the region.

In 1940s the construction of tin extracting industry and uranium mine was initiated. The uranium mine was functioning up to 1953.

A new stage in the industrial development of the region began since the late 1950s, when new gold, tin and wolfram deposits were discovered. There were created mining and processing facilities. Many settlements of workers around the deposits were created. In 1970s the mercury deposit was discovered. Gold mining in the district was developing and reached its highest point in 1974 (more than $36 \mathrm{tn}$. were mined). In the next years the mining volumes decreased due to depleting. Up to 1990 gold mining was about 15-19 tn. per year.

Later on, the economic crisis of the post-soviet period influenced the mining industry of the region. Massive loss of jobs in the mining sector led to mass outflow of people from the region. Exploration works were almost frozen and tin and wolfram extraction was totally suspended. The gold mining was performed by only small groups of workers with the total mining volume of less than $5 \mathrm{tn}$. per year. All the workers' settlements were liquidated.

Since the year 2000 foreign investors showed their interest in the main gold and silver mines of the region. Mining was renewed, new settlements of workers were created. The alluvial mining volumes decreased however, while the gold ore mining went sharply up. In 2008 for the first time since the last 20 years the production volume exceeded $20 \mathrm{tn}$. It became possible because of commissioning of a new gold mine. During all the industrial mining period 
of Chukotka autonomous district it was produced over 900 tn. of gold, 200 tsd. tn. of tin and 90 tsd. tn. of wolfram oxide. An extremely prominent is copper deposit, which is one of the largest in the world. However, lack of transport infrastructure and enormous investments needed inhibit the development of the deposit.

Other industries of the region besides of mining are developed poorly. These are small fish processing firms and producers of construction materials, which are concentrated primarily on the intraregional needs.

Agriculture. Despite of unfavorable climate conditions the agricultural segment is developing. However it could never satisfy the local needs in the full scope.

The main agricultural development direction is reindeer farming. The Chukotka pack of reindeers is one of the largest in the world. In 1970 the number of reindeers was about 587 tsd. livestock ( $25 \%$ of the world total). In the early 2000 it was a reduction of over 5 times. Besides of meat and skin the important medical raw material such as antlers is prepared.

Another important agricultural segment is hunting. Hunting of wild reindeers provides local population with diet meat. There is also hunting for moose, wolves, wolverines, bears, American minks, sables, Arctic foxes, muskrats, hares and ermines. The most prominent type of fowl is partridge [2].

Sea hunting and fishing is traditional among the population of the coastal settlements. One hunts walrus, seals, ringed seals, bearded seals. Fishing is primarily salmon. In some settlements one can find some fur farming.

In many Chukotka settlements population is engaged with greenhouse farming. In central and western parts of the district, in the non-freezing zones, an open-air cultivation of potatoes, cabbage and reddish takes place.

For hay gathering the meadows of the drained thermo-karst lakes are used.

Transport system. Chukotka district can be distinguished for its poor transport system; this is stipulated by low population density as well as severe climate conditions (winter lasts up to 9 months). So, road building becomes very costly and technically difficult. Today roads with pavement exist only in cities and the nearby settlements. The rest of the territory has the so called winter roads with no pavement. This roads are made of tamped snow, so they can be used only during winter time. For transportation one uses all-terrain vehicles, snowmobiles and trucks with enhanced off-road mobility.

There are no railway roads in the district. In some places one can find only narrow-gauge railway roads that serve local industrial purposes.

The main types of transport for long distances are by sea and by air. Every city has an airport. Despite of geographical proximity to Alaska there are no regular transport connections by sea or by air with it.

Maritime traffic can be also difficult during the freeze-up or ice break-up periods.

There are 5 seaports of the Northern Sea Route functioning in the region [3]. 


\section{Theoretical background of sustainable development}

The development program of Chukotka autonomous district assumes creation of the development model of the human activity spheres in the arctic region. Further the created model is to be used for analysis of development sustainability. The model creation demands for analysis of the human activity spheres in Chukotka autonomous district and for historical analysis of sustainable development researching. While understanding sustainable development as a process we inevitably touch upon the question of an equilibrium, because during the development process all socio-economic systems pass from one equilibrium state to another.

The analysis of scientific research in the sphere of sustainable development shows that research during many years was based on different theoretical and methodological approaches to the problem of equilibrium of socio-economic systems. The existence of sustainable development trajectory was justified in the fundamental research works of classical economists such as Leontief, Solow, Stiglitz, Hartwick, Barbier, Gylfason, Daly, Kvaerner, Markandya, Rennings, Hubert, Anders et al. [4-9].

Regional factors of economic growth and sustainable development as well as approaches to modeling of sustainable development were developed in the works of the following economists: Blam, Granberg, Goubaidoullina, Gourman, Dnilov-Danilyan, Doumova, Kleiner, Lossev, Seliverstov, Tatarkin et al. [1012]. As a general methodology of sustainable development of regional socioeconomic system a theory of economic dynamics can be taken. This theory was developed in the research works of Kondratiev, Schumpeter, Harrod, Kudland, Prescott, Menshikov, Klimenko, Yakovets. A synergetic paradigm of regional socio-economic development is based on conclusions presented in the works of Prigozhin, Stengers, Wag. The concept of transition from "spatial economics" to "time economics" as a condition of innovative production was developed in the works of Bekov, Yu. Mamedov, Inshakov, Ossipov.

The complex assessment of the regional sustainable development includes 3 aspects: industrial development of the territory, development of the social sphere, environmental condition of the territory. Every aspect is assessed with a system of indicators. The industrial development is evaluated with the indicators: - a share of GRP of the region in the total sum of all GRPs; - a share of regional export in the total Russian export; - a shipped volume of regional production. The development of the social sphere is assessed with the indicators: - level of income of the population and development level of the social infrastructure. Environmental conditions are characterized by harmful emissions to the atmosphere. The sustainable development of the territory within the region means balanced development of all the spheres in the region, i.e. the state where positive changes in one sphere do not incur neither negative dynamics of the indicators of the other spheres nor negative dynamics of the composite human development index of the region.

The author meaning of the category "sustainable regional development" is introduced. It is viewed as a managed process of development within the three 3 
spheres of human activity in the region. The balanced development of the spheres is being controlled in order to increase the human development potential. The human development potential is evaluated with the human development index.

\section{The methodology of model creation}

The methodological principles of model creation are determined by the choice of system of related econometric equations that serve to describe the development process within the 3 spheres of human activity of Chukotka autonomous district. The main basics of model creation are described below.

Selection of exogenous and endogenous variables. Comprehensive analysis made up the choice of the following endogenous variables: $y_{t}^{1}-$ the share of Chukotka gross regional product(GRP) in the total sum of Russian GRPs; $y_{t}^{2}-$ the share of regional export in the total Russian export; $y_{t}^{3}-$ the level of income of Chukotka population; $y_{t}^{4}-$ harmful emissions from stationary sources within the region to the atmosphere; $y_{t}^{5}-$ the share of shipped production of the region in the total shipped production of the Russian Federation; $y_{t}^{6}-$ the level of development of the infrastructural industries of the region.

It is assumed that every endogenous variable depends on the same endogenous variable taken with some lag as well as on other variables presented as time series. The distributed lag method enables research of dependencies of that kind $[13,14]$.

We assume that $y_{t}^{1}$ depends on $y_{t-1}^{1}$ and on the previous values of the indicators: the level of income of Chukotka population $\left(y_{t-j}^{3}\right)$, payments for import of technologies and technical services $\left(x_{t-i}^{1}\right)$, level of labor productivity $\left(x_{t-i}^{2}\right)$, number of doctor calls $\left(x_{t-i}^{3}\right)$.

We assume that $y_{t}^{2}$ depends on $y_{t-1}^{2}$ and on the previous values of the indicators: the share of shipped production of the region in the total shipped production of the Russian Federation $\left(y_{t}^{5}\right)$, growth rate of labor productivity $\left(x_{t-i}^{5}\right)$, the development level of manufacturing $\left(x_{t-i}^{6}\right)$.

We assume that $y_{t}^{3}$ depends on $y_{t-1}^{3}$ and on the previous values of the indicators: the share of Chukotka GRP in the total sum of Russian GRPs $\left(y_{t}^{1}\right)$, harmful emissions from stationary sources within the region to the atmosphere $\left(y_{t}^{4}\right)$, growth rate of labor productivity $\left(x_{t-i}^{5}\right)$, population growth $\left(x_{t}^{7}\right)$.

We assume that $y_{t}^{4}$ depends on $y_{t-i}^{4}$ and on the previous values of the indicators: the share of shipped production of the region in the total shipped 
production of the Russian Federation ( $\left.y_{t}^{5}\right)$, energy consumption $\left(x_{t}^{8}\right)$, the number of families living in the region $\left(x_{t}^{9}\right)$.

We assume that $y_{t}^{5}$ depends on $y_{t-1}^{5}$ and on the previous values of the indicators: the level of income of regional population $\left(y_{t-j}^{3}\right)$, labor productivity $\left(x_{t}^{2}\right)$, spending for technological innovations $\left(x_{t}^{4}\right)$.

We assume that $y_{t}^{6}$ depends on $y_{t-1}^{6}$ and on the previous values of the indicators: the share of Chukotka GRP in the total sum of Russian GRPs $\left(y_{t}^{1}\right)$, the level of income of the regional population $\left(y_{t}^{3}\right)$, the growth rate of labor productivity $\left(x_{t}^{5}\right)$, the development level of manufacturing $\left(x_{t-i}^{6}\right)$, population growth $\left(x_{t}^{7}\right)$.

For carrying out of analysis under these assumptions the ADL-model was chosen. The model enables the assess dependencies of the values on current and previous time series of other indicators [15].

The selection of the lags for the variables in time series, which show strong correlation with the indicator of the last period, i.e. checking for autocorrelation of the indicators in all the time series. The lags with strong correlation with the indicator for the last period are selected. The significance of the autocorrelation coefficients is tested with the Q-statistics (Ljung-Box test) [16].

Checking of endogenous and exogenous parameters for multicollinearity, composing of the correlation matrix, consideration of the pairs of variables with correlation coefficient over 0.8 , selection of one variable for the further analysis.

Analysis of time series for stationarity with the DF-test (Dickey-Fuller test).

Presentation of the system of equations in the structural view.

The structural form of the model makes visible the influence of any exogenous variable on the endogenous variable.

The identification of the system of equations. The procedure of testing of the structural form of the model for the necessary and sufficient conditions of identifiability [16-18].

The necessary condition of identifiability: comparison of $M-m$ with $k-1$ (where $M$ is the number of pre-identified variables of the model; $m$ is the number of pre-identified variables in the equation; $K$ is the number of endogenous variables of the model; and $k$ is the number of endogenous variables in the equation).

The sufficient condition of the identification for an equation is fulfilled if the rank of the sub matrix (that is composed only of the coefficients of the variables that are not presented in the equation) equals the number of endogenous variables minus one.

If the sufficient condition of the identification is fulfilled for every equation of the system then all the equations are super-identified (there are no unidentified equations in the system). This means that the whole model is also 
super-identified and, hence, the two stage least squares method is to be applied for determining the parameters of the equations.

If the structural form of the system of simultaneous equations is identified, then the indirect OLS method should be applied for determining the parameters of the equations. The OLS algorithm is realized in 3 steps: 1) on the basis of the structural form of the system of simultaneous equations the reduced form is constructed where the parameters are expressed with the structural coefficients; 2) the coefficients of every equation are assessed with the OLS method; 3) on the basis of the assessments of the coefficients in the system of simultaneous equations the structural coefficients are determined with the equations in the reduced form.

The transformation of the structural model to the model in the reduced form.

Transformation means a set of iterations resulting in no $y_{t}^{i}$ left in the right side of the equations.

The assessment of the parameters of the structural system: the adequacy assessment (accuracy) of the equations in the reduced form of the model is carried out with F-statistic; determining of the coefficients of the reduced form of the model with the OLS-method.

The first step of the model assessment is assessment of the adequacy (accuracy) of the equations. The mathematical equation is checked for adequacy with the empirical data. This means also checking for sufficiency of the included independent indicators that influence the resulting variable. The check for adequacy of the regression equation is generally performed with the Fstatistic.

The second step is determining of the coefficients of the structural form of the model. With the help of the reduced form for all super-identified equations the theoretical values of the endogenous variables in the left side of the equation are determined by putting the initial values of the exogenous variables to the right side of the obtained system of equations. So we get the table of theoretical values of the endogenous variables.

Further, putting the obtained theoretical values of the endogenous variables instead of actual values and using the simple OLS method we determine the equation coefficients for the structural form of all the super-identified equations.

\section{Descriptive statistics}

The time series of endogenous and exogenous variables are formed with data obtained from regional subsidiaries of the Federal Statistics committee of the Russian Federation

http://www.fedstat.ru/indicator/data.do;

http://www.gks.ru/bgd/regl/b13_14p/IssWWW.exe/Stg/d1/04-02.htm;

http://www.gks.ru/bgd/regl/b13_14p/IssWWW.exe/Stg/d2/13-01.htm;

http://www.gks.ru/bgd/regl/b13_14p/IssWWW.exe/Stg/d3/21-16.htm;

http://www.gks.ru/bgd/regl/b14_11/IssWWW.exe/Stg/d02/26-03.htm; 
http://www.gks.ru/free_doc/new_site/perepis2010/croc/perepis_itogi1612.htm; http://www.gks.ru/wps/wcm/connect/rosstat_main/rosstat/ru/statistics/enterprise/ industrial/.

\section{The results of the research - the model of economic development of Chukotka autonomous district}

As a result of complying with the principles of creation of sustainable development model we obtained the model of economic development of Chukotka autonomous district in the type of initial structural model (1) of 6 equations. Later on after analysis of the initial data the model can be transformed to the model in the reduced form:

$$
\left\{\begin{array}{l}
y_{t}^{1}=a_{0}+a_{1} y_{t-1}^{1}+\ldots a_{i} y_{t-i}^{1} \ldots+b_{1} y_{t-1}^{3} \ldots+c_{1} x_{t-i}^{1}+c_{2} x_{t-i}^{2}+c_{3} x_{t-i}^{3} \\
y_{t}^{2}=a_{0}+a_{1} y_{t-1}^{2}+\ldots+a_{i} y_{t-i}^{2} \ldots+b_{1} y_{t-1}^{5} \ldots+c_{1} x_{t-i}^{4}+c_{2} x_{t-i}^{5}+c_{3} x_{t-i}^{6} \\
y_{t}^{3}=a_{0}+a_{1} y_{t-1}^{3}+\ldots+a_{i} y_{t-i}^{3} \ldots+b_{1} y_{t-1}^{1} \ldots+b_{2} y_{t-1}^{4} \ldots+c_{2} x_{t-i}^{5}+c_{3} x_{t-i}^{7} \\
y_{t}^{4}=a_{0}+a_{1} y_{t-1}^{4}+\ldots+a_{i} y_{t-i}^{4} \ldots+b_{1} y_{t-1}^{5} \ldots+b_{2} x_{t-i}^{8}+b_{3} x_{t-i}^{9} \\
y_{t}^{5}=a_{0}+a_{1} y_{t-1}^{5}+\ldots+a_{i} y_{t-i}^{5} \ldots+b_{1} y_{t-1}^{3} \ldots+b_{2} x_{t-i}^{2}+b_{3} x_{t-i}^{4} \\
y_{t}^{6}=a_{0}+a_{1} y_{t-1}^{6}+\ldots+a_{i} y_{t-i}^{6} \ldots+b_{1} y_{t-1}^{1} \ldots+b_{2} y_{t-1}^{3} \ldots+c_{1} x_{t-i}^{5}+d_{1} x_{t-i}^{6}
\end{array}\right\}
$$

The assessment of the autocorrelation of the endogenous variables for selection of the lags in the time series has shown that the highest coefficients are observed only for variables $y_{t-1}^{4}$ and $y_{t-1}^{5}$. The coefficients are 0.69298 and 0.75823 respectively. That means that the variables of harmful emissions from stationary sources within the region to the atmosphere and the share of shipped production of the region in the total shipped production of the Russian Federation are included in the model with the lag $t-1$.

As a result of the multicollinearity test of the endogenous and exogenous variables the exogenous variables with correlation lower than 0.6 were excluded from the model. The analysis has shown, that four endogenous variables $\left(y_{t}^{3}\right.$, $y_{t}^{4}, y_{t}^{5}, y_{t}^{6}$ ) have a relatively high correlation (the maximum coefficient equals $0.61734)$ with endogenous variables with the lag $t-1\left(y_{t-1}^{1}, y_{t-1}^{5}, y_{t-1}^{3}, y_{t-1}^{1}\right)$. The variables with the lag $t-1$ are included into the model.

While analyzing of time series for stationarity the Dickey-Fuller test was performed with the Eview software for every time series. The analysis of one of the indicators - the share of the GRP in the sum of the Russian GRPs - is presented below in the table 1 .

The t-statistic of the coefficient equals -0.467572 , this value is lower than critical level of t-statistic for 5\% significance level (and even lower than $1 \%$ critical level) for the researched model. The critical level of t-statistics is -1.605603 . It means that with $1 \%$ level of significance the time series is stationary. 
Table 1: The results of the Dickey-Fuller test for stationarity of the time series. The share of the GRP in the sum of the Russian GRPs.

\begin{tabular}{|c|c|c|c|}
\hline \multicolumn{2}{|c|}{ Augmented Dickey-Fuller test statistic } & t-Statistic & Prob.* \\
\cline { 3 - 4 } & -0.467572 & 0.4966 \\
\hline Test critical values: & $1 \%$ level & -2.717511 & \\
\hline & $5 \%$ level & -1.964418 & \\
\hline & $10 \%$ level & -1.605603 & \\
\hline
\end{tabular}

The check for identificability conditions shows that the necessary and sufficient conditions of identificability are fulfilled. The structured form of the system of simultaneous equations is precisely identified, i.e. for determining the equations parameters the indirect OLS-method should be applied.

For finding the coefficients of the regression equations the SPSS Statistics 2.0 software was used.

After the analysis of the initial data, selection of the data that corresponds to the model creation principles and determining of the regression coefficients for the system of equations, the structural form of the model is the following (2):

$$
\left\{\begin{array}{l}
y_{t}^{1}=-0,299+0,00000649 x_{t-1}^{1}-0,000001942 x_{t-1}^{3} \\
y_{t}^{2}=0,800+0,777 x_{t-1}^{5}-0,805 x_{t-1}^{6} \\
y_{t}^{3}=645,007+1204,669 y_{t-1}^{1}-557,569 x_{t-1}^{5} \\
y_{t}^{4}=0,347+521,722 y_{t-1}^{4}-3,405 x_{t-1}^{8}+0,191 x_{t-1}^{9} \\
y_{t}^{5}=-2,690+22,49 y_{t-1}^{5}+0,088 y_{t-1}^{3} \\
y_{t}^{6}=0,877+5,03 x_{t-1}^{6}+0,31 y_{t-1}^{1}
\end{array}\right\}
$$

Transformation of the system of equations (2) with the substitution method made it possible to get the reduced form of the model. The number of equations in the reduced form is equal to the number of endogenous variables of the model. Each equation of the reduced form expresses an endogenous variable with all the pre-defined variables of the model. The right side of each equation consists only of the pre-defined variables and residues and the left side is only one of the endogenous variables. That means that the whole system is a system of independent equations.

So we obtain the system of independent equations in the reduced form (3):

$$
\left\{\begin{array}{l}
y_{t}^{1}=-0,299+0,00000649 x_{t-1}^{1}-0,000001942 x_{t-1}^{3} \\
y_{t}^{2}=0,800+0,777 x_{t-1}^{5}-0,805 x_{t-1}^{6} \\
y_{t}^{3}=645,007+360,196 y_{t-1}^{1}+0,008 x_{t-1}^{1}-0,002 x_{t-1}^{3}-557,569 x_{t-1}^{5} \\
y_{t}^{4}=0,347+521,722 y_{t-1}^{4}-3,405 x_{t-1}^{8}+0,191 x_{t-1}^{9} \\
y_{t}^{5}=54,071+22,49 y_{t-1}^{5}-31,697 x_{t-1}^{1}-0,00176 x_{t-1}^{3}-49,066 x_{t-1}^{5} \\
y_{t}^{6}=0,784+0,00000201 x_{t-1}^{1}-0,0000006 x_{t-1}^{3}+5,03 x_{t-1}^{6}
\end{array}\right\}
$$




\section{Conclusion}

The described model consists of six econometric equations and includes six endogenous variables. The variables such as the share of the GRP in the sum of the Russian GRPs; the share of regional export in the total Russian export; the level of income of the population; the level of development of the infrastructural industries of the region are influenced only by exogenous variables with the lag $t-1$. The variables such as harmful emissions from stationary sources within the region to the atmosphere; the share of shipped production of the region in the total shipped production of the Russian Federation are influenced by exogenous variables with the lag t-1 and by the similar endogenous variables with the same lag.

The presented model is the core of the sustainable regional development concept. This development is a managed process of development of the three sectors of human activities. The balanced development of the spheres is controlled in order to increase the human development potential. The following order is meant: the growth and forecast for the industrial, social and ecological spheres are estimated according to the indicators of the model. The manageability of the development process within these three spheres of human activity depends on control of the balanced development of the spheres and on the analysis of the human development index dynamics.

\section{Acknowledgement}

This paper is based on research carried out with the financial support of the grant of the Russian Scientific Foundation (Project No. 14-38-00009), St. Petersburg Polytechnic University.

\section{References}

[1] Oar deposits of the Russian Arctic. Website: www.arctictoday.ru - Dec. 7, 2011.

[2] Yu. N. Golubchkov. The geography of Chukotka autonomous district. Moscow, Publishing house "Design. Information. Cartography", 2003.

[3] A.V. Belikovich, A.V. Galanin Chukotka: natural and economic review. Moscow, Publishing house “Art-Liteks", pp. 98-99, 1995.

[4] Crosier S. Johann-Heinrich von Thünen: Balancing Land-Use Allocation with Transport Cost / Center for Spatially Integrated Social Science.

[5] Duranton G. Spatial Economics / The New Palgrave Dictionary of Economics. Second Edition. Eds. Steven N. Durlauf and Lawrence E. Blume. Palgrave Macmillan, 2008.

[6] Hoover E.M. Spatial Economics: The Partial Equilibrium Approach International Encyclopedia of the Social Sciences (January 1968).

[7] Kasper W. Spatial Economics / The Concise Encyclopedia of Economics / Econlib Web-site: http://www.econlib.org/. 
[8] Korenik S., Miszczak K. Region as a Fundamental Unit in Modern Spatial Economy / Spatial Economy and Self-governed Administration Wroclaw University of Economics / GeoScape 6(1-2), pp. 11-17, 2011.

[9] Krugman P. R. The Role of Geography in Development // International Regional Science Review. Vol. 22. - № 2, pp. 142-161, 1999.

[10] P.A. Minakir. Economics and space (theses of reflection) / Spatial economics, №1 pp. 4-26, 2005.

[11] A.G. Granberg. Spatial economics in the set of sciences /"The new economic association" journal, web-site: http://www.econorus.org/.

[12] Collective monograph: B.N. Porfiriev, D.O. Eliseev, F.D. Laritchkin, A.I. Tatarkin, A.I. Shishkin, P.A. Minakir, V.M. Katsov, V.V. Kouleshov, V.A. Tsvetkov, E.A. Zakhartchuk, V.N. Lazhentsev, D.A. Gaynanov, S.V. Kouznetsov. The Russian Arctic: the modern development paradigm / edited by academic A.I. Tatarkin, St. Petersburg, Publishing house "Nestor-History", p. 844, 2014.

[13] J. Box, G. Jenkins, Time series analysis. Forecast and management, Moscow, pp. 66-69, 1974

[14] Didenko N., Kunze K. Relationship between Energy Policies and Quality of Life in Russia. WIT Transactions on Ecology and the Environment, Vol 186, WIT Press, 2014, ISSN 1743-3541.

[15] V.I. Souslov, N.M. Ibragimov, L.P. Talysheva, A.A. Tsyplakova. Econometrics. Novosibirsk, Russian Academy of Science, p. 744, ISBN 57692-0755-8, 2005.

[16] The systems of econometric equations. http://math.semestr.ru/regress/ systems.php.

[17] Structural and reduced forms of the econometric equations system. http://ekonometred.ru/bilety-k-ekzamenu-ekonometrika/61-strukturnaya-iprivedennaya-formy-modeli-sistemy.html.

[18] Econometrics. Textbook / Edited by F.L. Sharov, Moscow, p. 128, 2009. 